\title{
La incorporación como doctrina: observaciones para una teoría del error
}

\section{POR RICARDO MARQUISIO (*)}

Sumario: I. Introducción.- II. La unidad del razonamiento práctico.III. La incorporación como teoría.- IV. La incorporación como doctrina.- V. La teoría del error.- VI. El error de la doctrina de la incorporación.- VII. ¿Y ahora qué?- VIII. Conclusiones.- IX. Bibliografía.

Resumen: en este artículo analizo el uso como argumento para resolver casos jurídicos de la idea de que la moral se incorpora al derecho a través de la mención de principios y derechos por las fuentes sociales. Luego de presentar una distinción entre la incorporación como teoría y la incorporación como doctrina, abordo esta última desde las categorías de la teoría del error. Tomando como ejemplo una decisión judicial basada en la doctrina de la incorporación, concluyo que esta constituye un error generalizado, en tanto es incompatible con la caracterización del sistema jurídico que presuponen sus referencias teóricas. Dejar de lado la doctrina de la incorporación constituiría una ganancia para la práctica jurídica, tanto en sinceridad como en responsabilidad democrática.

Palabras claves: teoría de la incorporación - decisión judicial - moral y derecho - teoría del error

\section{The incorporation as a doctrine: observations for an error theory}

Abstract: in this paper I analyze the use as an argument to solve legal cases of the idea that morality is incorporated into law through the mention of principles and rights by social sources. After presenting a distinction between incorporation as theory and incorporation as a doctrine, I approach the latter from the categories of error theory. Taking as an example a judicial decision based on the doctrine of incorporation, I conclude that this constitutes a generalized error, inasmuch as it is incompatible with the characterization of the legal system that its theoretical references presuppose. Leaving aside the doctrine of incorporation would be a gain for legal practice, both in sincerity and in democratic responsibility.

(*) Prof. Agregado de Filosofía y Teoría General del Derecho, Facultad de Derecho, Universidad de la República (FDER-UDELAR), Uruguay. 


\begin{abstract}
Keywords: incorporation theory - judicial adjudication - morality and law error theory
\end{abstract}

\title{
I. Introducción
}

La Suprema Corte de Justicia de Uruguay declaró inconstitucional una disposición legal que preveía un listado de medicamentos de acceso general para la población, argumentando que el establecimiento de cualquier nomina en ese sentido, vulnera un derecho a absoluto a la salud, consagrado en la Carta(1). El Tribunal de lo Contencioso Administrativo, también de Uruguay, falló contra la posibilidad de que sea exigida, como requisito para desempeñar un cargo público, la realización de mamografías periódicas a las mujeres mayores de cierta edad, por considerar que, interpretada desde la Constitución, la legislación no puede imponer esa condición, en cuanto viola un derecho humano fundamental incorporado al ordenamiento (2). El Tribunal Constitucional Plurinacional de Bolivia sentenció la inconstitucionalidad de una limitación a la reelección indefinida de los gobernantes, incluida en una disposición constitucional, con el fundamento de que atenta contra un principio de igualdad recogido por un pacto internacional(3). Numerosos autores de doctrina, en todas las ramas del derecho, consideran que el artículo 72 de la Constitución uruguaya implica el ingreso al sistema jurídico de un vasto e indeterminado set de principios y derechos, cuya invocación es suficiente para resolver casos jurídicos (4).

Los ejemplos anteriores tomados entre muchísimos posibles, responden a un discurso extendido en la práctica jurídica contemporánea (5): la doctrina de la incorporación de la moral al derecho. Según este discurso, la moral ingresa a las instituciones jurídicas a través de las normas constitucionales y supranacionales (pactos internacionales), porque estas incluyen la mención de principios y derechos, vagos y abstractos. Dichas normas, a las que se interpreta como un puente

(1) Sentencia 396/2016, de 05/10/2016.

(2) Sentencia 396/2016 de 19/07/2016.

(3) Sentencia Constitucional 0084/2017 de 28/11/2017.

(4) La doctrina de la incorporación es virtualmente incontestada en la práctica jurídica uruguaya, en especial a partir de la interpretación corriente del artículo 72 de la Constitución (Marquisio, 2018a). Un panorama de su influencia en dogmática y jurisprudencia se encuentra en Tovagliare, Van Rompaey y Barbieri, 2016.

(5) En la práctica jurídica incluyo a la decisión judicial y la dogmática. Pese a que esta última se suele considerar dentro de lo que - con mucha ambigüedad y vaguedad — se denomina ciencia del derecho (Núñez Vaquero, 2015) se trata, en verdad, de una técnica social que no tiene como objetivo aportar conocimiento sino influir en la conducta de los jueces (Ruiz Miguel, 2002). Esto es válido no solo para la dogmática tradicional normativista, sino también para la que se concibe a sí misma como crítica y se ubica de manera explícita al servicio de objetivos políticos (Bovino y Courtis, 2009). 
entre el derecho y la moral, son invocadas como razones, por sí solas, determinantes para resolver los casos jurídicos. La mera mención de un principio moral incorporado permite, desde esta visión, derrotar a los criterios establecidos por reglas legales y constitucionales, incluso aquellos que no ofrecen mayores dificultades interpretativas.

La doctrina incorporacionista es considerada, tanto por sus críticos como por sus partidarios, como una suerte de moralización del derecho, asociada a concepciones iusnaturalistas o pos positivistas, a la que se atribuye la pretensión de superarlos rigorismos y excesos normativistas que muchas veces se endilgan (sin razón) al positivismo jurídico (6).

En apariencia, la doctrina de la incorporación podría verse como una suerte de implicancia o corolario práctico del positivismo suave, emergente del debate Hart/Dworkin. Esto es, la línea de respuesta que, aceptando algunas de las críticas de Dworkin al positivismo tradicional, procedió a la reformulación de sus tesis, principalmente la de separación entre el derecho y la moral, a la que conceptualizó como separabilidad.

Mi planteo es que ese no es el caso. El incorporacionismo que invocan jueces y dogmáticos, como receta para transformar casos difíciles en fáciles o hasta triviales, no es validado, ni en sus presupuestos ni en sus propósitos, por la concepción teórica que dio lugar al positivismo inclusivo.

Para diferenciar ambos tipos de incorporacionismo llamaré al primero (objeto de mi crítica) doctrinal (D) y al segundo teórico (T). Luego de algunas consideraciones generales sobre el razonamiento práctico, dedicaré las siguientes dos secciones a la distinción entre ambos modelos. A continuación, presentaré un argumento según el cual el tipo de incorporacionismo que denomino doctrinal constituye una especie de malentendido generalizado, del que puede darse cuenta en términos de una teoría del error. Finalmente, realizaré algunas consideraciones sobre la necesidad de modificar la práctica basada afectada por el error constatado.

\section{La unidad del razonamiento práctico}

Uno de los puntos de mayor consenso en la teoría del derecho contemporánea es el rechazo de modelo formalista de razonamiento jurídico (7). Concepciones

(6) El positivismo contemporáneo es un proyecto cuya ambición mínima lo hace compatible con un amplio abanico de concepciones teóricas, dogmáticas y de la decisión judicial (ver Marquisio, 2017a).

(7) El formalismo del razonamiento jurídico consiste en la adopción de dos tesis. La primera es que el derecho está racionalmente determinado (las normas jurídicas aplicables establecen un solo 
filosóficas tan diferentes entre sí como las de Raz (1999), Dworkin (2011), Finnis (2011) y Alexy (1997) acuerdan en la unidad fundamental del razonamiento práctico. Esto significa que los casos jurídicos deben abordarse como problemas normativos tout court, donde el universo de razones relevantes es proporcionado por el punto de vista moral, en tanto el procedimiento de resolución y la atribución concreta de autoridad decisoria son aportados por el marco institucional relevante.

Las razones constituyen el elemento básico e irreductible del dominio normativo. Las razones morales constituyen un tipo de razones normativas prácticas: aquellas que se conectan con el punto de vista de la imparcialidad y toman en cuenta los intereses de los otros, con independencia de cualquier relación especial que puedan tener con el agente. La autonomía moral consiste en la capacidad de identificar razones morales, y motivarse a actuar de acuerdo con ellas (Marquisio, 2017b).

Los problemas normativos surgen cada vez que nos preguntamos, por el motivo que sea, acerca de qué debería ser del caso, tanto en las creencias (¿deberíamos confiar en el pronóstico del meteorólogo?) como en la acción (¿debo decirle la verdad a alguien, aunque ello dañe su autoestima sin ningún beneficio adicional?). Los problemas jurídicos pueden ser conceptualizados como aquellos donde, en el contexto institucional caracterizado por cierto tipo de reglas específicas(8), se plantean determinados reclamos sobre qué debería hacerse.

En palabras de Raz:

(...) no podemos concebir el derecho como un punto de vista válido normativamente que contraste con la moral. Quizás sea posible pensar en las razones de interés propio como un punto de vista distinto que contraste con el de la moral, pero eso, si es posible, lo es sólo porque se piensa que el propio interés constituye un fundamento de razones independiente de la moral. Pero no es igualmente posible pensar

resultado correcto para todos los casos jurídicos o al menos para la amplia mayoría de ellos). La segunda es que la adjudicación judicial requiere un razonamiento autónomo con respecto a otras clases de razonamiento práctico: los jueces (siempre o casi siempre) pueden resolver, de forma correcta, sin acudir a estándares normativos "no jurídicos" (morales, políticos, etc.) (Leiter, 2010).

(8) La idea de que los sistemas jurídicos son posibles a partir de la existencia de reglas secundarias (que regulan la identificación, modificación y aplicación de los estándares normativos relevantes) es una de las grandes contribuciones de Hart a la filosofía del derecho. Hart desarrollo, a partir de esa idea central, una caracterización positivista del sistema jurídico. Pero esta implicación no es necesaria. Tomar las reglas secundarias, como constitutivas de un marco institucional necesario para la adopción de decisiones (generales y particulares) comunitarias forma parte de los compromisos teóricos, tanto del iusnaturalismo como del interpretativismo dworkiniano (Ver Finnis, 1999, pp. 203-205; Dworkin, 2011, p. 405). 
en el derecho como en un fundamento de razones independiente de la moral; dado que en buena parte es producto de los hombres, al menos los derechos jurídicos creados por estos vinculan a sus destinatarios sólo si los principios morales de legitimidad los hacen vinculantes (Raz, 2013, p. 199).

Si hay unidad del razonamiento práctico, entonces, las razones jurídicas no son otra cosa que razones morales que se identifican en el contexto institucional del derecho. La denominada aplicación del derecho (decisión de los casos jurídicos sobre la base de reglas preexistentes) no elimina la necesidad del razonamiento moral, sino que le agrega una mayor complejidad. Al ya exigente balance de razones propio de la argumentación moral le agregamos nuevas razones: las normas provenientes de las fuentes sociales del derecho. La disputa más relevante entre diferentes teorías del derecho es, precisamente, sobre el modo en que el contexto institucional del derecho impacta sobre el razonamiento práctico. ¿La identificación de los estándares jurídicos es criterial o interpretativa? ¿Su normatividad puede depender de algún tipo de convención? ¿Puede distinguirse un razonamiento jurídico como "caso especial" en el marco de un razonamiento práctico general?

Una de estas controversias tiene que ver con el hecho de que en la práctica jurídica y en el lenguaje de las fuentes sociales se hace alusión a un vasto número de principios morales que, en una enunciación vaga y abstracta, aparecen en los textos constitucionales y pactos internacionales. Todo el mundo está de acuerdo en que el principio de igualdad o el derecho a no ser torturado constituyen estándares morales, en el sentido que constituyen exigencias de imparcialidad, cuyo cumplimiento nos debemos unos a otros (Scanlon, 2000)(9). El sentido de estas exigencias puede identificarse por cualquiera gente capaz de razonar en forma moralmente autónoma. El desacuerdo surge, sin embargo, cuando intentamos dar cuenta del sentido que tiene, para esa clase de agentes, la mención de estos principios en la legislación y las decisiones judiciales. ¿Significa que pasan a formar parte del derecho? ¿O suponen una especie de reenvío del derecho a la moral en el entendido de que la legislación atribuye a los jueces discrecionalidad para resolver según sus propios criterios morales?

\section{La incorporación como teoría}

El debate Hart-Dworkin constituye la referencia ineludible para entender el estado actual de la filosofía jurídica en torno al problema de relación entre la moral y

(9) El escepticismo moral no controvierte que esos principios y derechos sean conceptualmente caracterizados, como morales pero rechaza que ello implique alguna justificación para la acción, en tanto no acepta la existencia de valores morales objetivos (Sinnott-Armstrong, 2006). 
el derecho. La denominada tesis de la incorporación es una de las más trascendentes consecuencias de ese debate. Se trata de una propuesta destinada a defender al positivismo, entendido como una teoría conceptual, descriptiva y neutralmente valorativa, de los ataques de Dworkin, que le contraponía una visión interpretativa, prescriptiva y justificada en (y al servicio de) valores sustantivos.

Sobre el origen de la teoría de la incorporación es ilustrativo detenerse en el Postcriptum de Hart a la segunda edición de The Concept of Law.

Lo que Dworkin argumentaba era la imposibilidad de un modelo de teoría jurídica como el positivismo, en cuanto pretendía ser (I) "criterial” y (II) "de pedigrí", de dar cuenta del papel de los principios y otros estándares de contenido que son asumidos como obligatorios por los participantes de la práctica jurídica. En su respuesta, Hart defiende al positivismo como proyecto de teoría general, descriptiva y valorativamente neutral, aceptando (I) pero rechazando que implique (II).

Hart sostiene que un criterio fáctico de juridicidad - la regla de reconocimiento como práctica convergente de los tribunales- es necesario para que podamos hablar de un sistema jurídico. Sin embargo, no acepta que esa idea de validez, como facticidad en última instancia, implique que todos los estándares jurídicos deban ser identificados por una prueba de origen. La regla de reconocimiento puede, de modo contingente, incorporar criterios de validez basados en la conformidad con principios morales y otros valores sustantivos como sucede, por ejemplo, cuando la constitución incluye la mención del principio de igualdad, poniendo límites a la potestad de los legisladores de aprobar leyes de contenido discriminatorio. De manera expresa, endosa el denominado positivismo suave o inclusivo, cuyo núcleo teórico es precisamente la tesis de la incorporación (Hart, 1994, pp. 250-254). Hart adopta el positivismo suave porque cree que la tesis de la incorporación permite dar cuenta de cómo la regla de reconocimiento, en tanto regla social, puede contingentemente validar normas basadas en propiedades morales y esa es la mejor línea de respuesta al desafío de Dworkin (Ver Shapiro, 2009).

La réplica de Hart a Dworkin resume tres aspectos característicos de la tesis de la incorporación.

En primer lugar, implica la aceptación de un grado importante de incertidumbre en la identificación y determinación del derecho (algo que, en opinión de Hart, no es problemático para una teoría positivista). Los principios tienen un grado de vaguedad y abstracción mayor que las reglas, son múltiples y apuntan en direcciones contradictorias; en consecuencia imponen un alto nivel de complejidad y sofisticación en el razonamiento judicial a la hora de identificar (o establecer) lo que el derecho exige. 
En segundo lugar, la clase de incertidumbre generada por la incorporación no es la que se presenta en los casos difíciles asociados a la textura abierta del derecho (vaguedad, ambigüedad y otras dificultades interpretativas), que determinan que los abogados discrepen de buena fe sobre lo que la ley requiere. La incorporación de estándares morales a la regla de reconocimiento tiene como consecuencia una incompletitud fundamental del sistema jurídico: se asume que el derecho no proporciona respuesta en los casos que se deciden razonando acerca de lo que requiere esos estándares. La respuesta queda necesariamente diferida a la decisión de los jueces e implica que estos deban hacer su mayor esfuerzo por alcanzar la solución que puedan considerar mejor justificada.

En tercer lugar, la tesis de la incorporación se presenta como un modo de identificar el derecho que no presupone ninguna teoría meta ética y evita pronunciarse acerca de la objetividad de los juicios morales. El modo de identificación del derecho que plantea lleva de modo inevitable a la discrecionalidad judicial pues, con independencia de que exista una moral objetiva, la única guía que tendrá el juez para establecer el contenido del derecho, en los casos de incorporación de principios, será su propio juicio moral.

Para Dworkin, la tesis de la incorporación, en cuanto se enuncia para defender una caracterización criterial, convencional y neutral en lo valorativo del derecho, no solo no proporciona una explicación apropiada de cómo los estándares morales contribuyen a la identificación y determinación del derecho, sino que trivializa a la propia teoría positivista: transforma en convencionales por definición a todas las prácticas jurídicas de una comunidad, transforma en jurídicas por definición a todas las prácticas morales y desnaturaliza por completo la propia idea de convención (Dworkin, 2006, p. 193).

La teoría de la incorporación tampoco es compatible con las concepciones iusnaturalistas. Si bien es cierto que algunas teorías del derecho natural podrían entenderse como criteriales (Moore, 2006), ninguna califica como convencional, pues todas rechazan las restricciones basadas en convenciones a la presencia de estándares morales (razones para la acción) como parte intrínseca del razonamiento jurídico, y bajo ningún concepto pueden asociarse con la neutralidad valorativa (Finnis, 2016).

La tesis de la incorporación es controversial a la interna del positivismo. Los positivistas excluyentes la han atacado desde distintos ángulos. Algunos alegando su incompatibilidad con el escepticismo moral, al que consideran vinculado de forma necesaria con el positivismo jurídico (Bulygin, 2004). Otros, coincidiendo en este punto con Dworkin, cuestionan que la incorporación de la moral, como criterio de identificación de estándares jurídicos, pueda acomodarse a una caracterización convencional del derecho (Marmor, 2016). Por su parte, la línea de 
ataque que ha mostrado ser más influyente, se basa en la imposibilidad de incorporar criterios de identificación morales a la determinación de la validez jurídica, por ser ello incompatible con algún rasgo conceptual del derecho: su pretensión de autoridad legítima (Raz, 2009); su capacidad de constituir una diferencia en el juicio práctico (Shapiro, 1998); su condición de actividad necesaria para la planificación social (Shapiro, 2009).

La tesis de la incorporación ha sido abandonada por algunos de sus antiguos proponentes. En tal sentido, Himma argumenta que las normas morales no pueden constituir condiciones necesarias o suficientes de validez jurídica en ningún sistema que atribuya a un tribunal (la Suprema Corte o un Tribunal Constitucional) la última palabra sobre decisiones contrapuestas de otros tribunales, acerca de si una proposición de derecho es verdadera en virtud de su conformidad con normas morales. Resulta muy improbable, aunque no imposible en teoría, que existan sistemas jurídicos sin esta clase de última palabra en la adjudicación (Himma, 2005).

Por su parte, Coleman ha llegado a rechazar, tanto la idea de una regla de reconocimiento como la tesis de la separabilidad, e inclusive coincide con Dworkin en que la noción de criterio de juridicidad no forma parte del concepto de derecho. Para Coleman una adecuada caracterización del positivismo inclusivo no necesita acudir a la tesis de la incorporación (Coleman, 2009).

Se trata, por cierto, de un debate que está lejos considerarse concluido. Moreso continúa defendiendo la tesis de la incorporación que, a su juicio, da cuenta de la identificación del derecho por el razonamiento moral en los sistemas jurídicos contemporáneos, bajo el supuesto de dos condiciones: (I) que las remisiones a la moralidad sean limitadas y no impliquen que, en cada instancia de aplicación del derecho, intervenga la argumentación moral; (II) que la diferencia práctica del derecho vaya de la mano de su estructura institucional. Para Moreso la tesis de la incorporación resulta compatible con la postura del positivismo tradicional, en cuanto a que el derecho está conceptualmente separado de la moral, puesto que la incorporación no solo es contingente, sino que su propia posibilidad depende del contenido del tipo de normas jurídicas que se pretenda identificar. Algunas normas jurídicas necesitan ser opacas a las razones morales subyacentes y deben, por tanto, poder identificarse sin controversia ni variaciones: las reglas que confieren poderes, las reglas de adjudicación, las resoluciones individuales administrativas y jurisdiccionales, las reglas que establecen qué decisiones judiciales son definitivas. En cambio, otras como, por ejemplo, las que establecen penas para los delitos, son típicamente susceptibles de ser abiertas a consideraciones morales que determinen, por ejemplo, su compatibilidad con la Constitución, por lo que, a su respecto, la incorporación puede ser vista como un mecanismo de levantamiento 
progresivo del velo de la opacidad, en el marco de la estructura institucional que, como un todo, hace posible la diferencia práctica del derecho (Moreso, 2015).

Para Atria, en cambio, una vez que los positivistas suaves reconocen que la moral es condición de juridicidad en los sistemas contemporáneos, transforman al positivismo en una pura estipulación. Para mantener la etiqueta asociado a su tradición teórica, necesitan postular de órdenes jurídicos, a los cuales reconocen como inexistentes en la realidad e implausibles, que no incorporen en ningún caso condiciones morales a la validez jurídica. Por otra parte, las agudas controversias sobre cómo entender las cláusulas constitucionales que mencionan principios morales (por ejemplo, entre defensores de la lectura moral y originalistas) impiden hablar de convenciones interpretativas cuyo resultado sea un consenso en torno a la tesis de la incorporación (2016, pp. 43-46).

Un aspecto de la teoría de la incorporación merece ser subrayado: el "ingreso" de los estándares morales al sistema jurídico no modifica la función cumplen en el razonamiento moral. Según una trivialización de esta tesis, el denominado "argumento del Rey Midas", la formulación de los principios a partir de su mención por las fuentes sociales, implicaría la pérdida de su naturaleza moral. Es verdad que, dado el carácter institucional del razonamiento jurídico - las jueces son funcionarios sujetos a reglas de procedimiento- la introducción de los principios morales constitucionalizados se canalizará a través de las técnicas usuales de argumentación jurídica - uso de argumentos semánticos sobre la constitución, respeto de precedentes, invocación de analogías-. Sin embargo, el derecho no puede establecer de modo exhaustivo el significado de los principios morales "constitucionalizados". Y es precisamente por eso que se incluyen en la constitución pues, a su respecto, los ciudadanos han acordado una fórmula equitativa para expresar un cierto valor moral. El estándar permanece indeterminado y queda abierto a la posibilidad de aplicarlo a una variedad de circunstancias no previstas, a la continuidad de la discusión de su contenido y a la revisión de las interpretaciones pasadas, en función del cambio de las condiciones sociales y los valores imperantes (Pino, 2014, pp. 209-210).

\section{La incorporación como doctrina}

La tesis de la incorporación, formulada por los positivistas suaves, resulta un intento de dar cuenta de la relevancia de la moral para los sistemas jurídicos, manteniendo a la teoría del derecho estrictamente en el punto de vista externo. La incorporación de la moral al derecho se afirma desde la perspectiva del observador que reconstruye la práctica de los participantes (fundamentalmente el discurso de los jueces), determinando cuáles son las convenciones vigentes, para arribar a la 
conclusión de que estas incorporan criterios morales, como condición necesaria o suficiente de la validez jurídica.

Sin embargo, el lenguaje incorporacionista, tal como se utiliza con frecuencia en la dogmática y la decisión judicial, excede de manera notoria los supuestos y propósitos de la teoría de la incorporación.

Tomando la terminología que Dworkin adopta para discutir el concepto de derecho, llamaré doctrinal a este uso del lenguaje incorporacionista. Dworkin utiliza la idea de sentido doctrinal del derecho (contrastándolo con los que denomina conceptos aspiracionales y sociológicos) con referencia a las proposiciones que afirman lo que este prohíbe o permite en una comunidad en particular. De acuerdo con Dworkin, utilizamos el concepto de derecho en sentido doctrinal cuando hacemos afirmaciones sobre cuál es la solución correcta de un caso jurídico (Dworkin, 2006, p. 2).

En este sentido, la afirmación de que la moral se incorpora al derecho a través de las menciones en la constitución o pactos internacionales puede entenderse como doctrinal (D) si se invoca como razón concluyente para dar solución a un caso jurídico general o individual.

En la concepción interpretativa de Dworkin, entendida como una teoría de sistema único donde no hay, propiamente, relación entre derecho y moral (el derecho es parte de la moral política institucionalizada de la comunidad), el incorporacionismo doctrinal (al igual que el teórico) carece de sentido. Desde una visión integrada, moral y derecho no describen colecciones de normas pertenecientes a órdenes diferentes, sino que el último es una subdivisión de la moral política (que a su vez es una continuidad de la moral personal y de la ética, en una estructura ramificada que toma como punto de partida los valores prácticos más abstractos) (Dworkin, 2011, p. 405). Aquí la idea de incorporar la moral al derecho no tiene razón de ser teórica (no puede dar cuenta de las condiciones que hacen verificables las proposiciones de derecho) ni doctrinal (el derecho es, en sí mismo, una estructura moral comunitaria, que se expresa institucionalmente, y la solución de los casos difíciles depende de un argumento reconstructivo de su mejor historia).

Voy a tomar el primer caso de los citados en la introducción para mostrar como la doctrina de la incorporación invoca al ingreso, mediado constitucionalmente, de la moral al derecho, como un argumento tan concluyente que elimina la necesidad de toda otra consideración valorativa.

En el año 2016, la Suprema Corte de Justicia de Uruguay falló sobre una solicitud de inconstitucionalidad del artículo 7 , inc. $2^{\circ}$ de la ley $\mathrm{N}^{\circ}$ 18.355. La disposición atacada establecía que "todo paciente tiene el derecho a acceder a medicamentos 
LA INCORPORACIÓN COMO DOCTRINA: OBSERVACIONES PARA UNA TEORÍA DEL ERROR

- RICARDO MARQUISIO (PP. 659-680)

de calidad, debidamente autorizados por el Ministerio de Salud Pública (MSP) e incluidos por este en el formulario terapéutico".

La inconstitucionalidad de la norma provenía, según la Corte, de su contradicción con el artículo 44 de la Constitución que establece: "El Estado legislará en todas las cuestiones relacionadas con la salud e higiene públicas, procurando el perfeccionamiento físico, moral y social de todos los habitantes del país. Todos los habitantes tienen el deber de cuidar su salud, así como de asistirse en caso de enfermedad. El Estado proporcionará gratuitamente los medios de prevención y de asistencia tan solo a los indigentes o carentes de recurso".

La Corte entendió que la ley impugnada violaba el citado artículo 44 porque, al establecer una lista de medicamentos a que los usuarios tienen derecho, dejaba abierta la posibilidad de limitar a un derecho que no admite la menor restricción. Se trata, dice según la sentencia, "de una norma regresiva, que tiende a limitar los medios médicos disponibles de prevención, tratamiento y asistencia, contradiciendo de esta forma la norma de rango superior". El núcleo del argumento es que: (I) el artículo 44 incorpora al ordenamiento uruguayo el derecho (moral) a la salud; (II) lo que se incorpora es un derecho que no admite ninguna clase de limitación, es decir, un derecho absoluto; (III) cualquier lista de medicamentos que estipulara el Ministerio de Salud Pública sería limitativa y, por tanto, violaría el derecho absoluto a la salud.

El punto no es aquí el dilema humano que se plantea al fallar sobre casos como este, donde está en juego una pretensión judicial cuya satisfacción es de vida o muerte para quien la deduce(10). Tampoco las contradicciones a las que lleva considerar, en un razonamiento formalista como el expuesto, a la salud como un derecho absoluto (11). Lo que me interesa plantear es el uso de la incorporación como razón suficiente para la decisión y los supuestos sobre el derecho que ello implica.

(10) El reclamo de un medicamento para conservar la vida, ante la negativa del Estado a proporcionarlo, excede los parámetros del caso difícil, ingresando en la órbita de los casos trágicos, donde no es posible un balance de razones satisfactorio y la solución debe atender a elementos emocionales que desbordan las exigencias argumentativas (Atienza, 1997). El problema no es que la Corte considere que el Estado debe proporcionar los medicamentos necesarios (lo que no me parece en absoluto criticable y, por el contrario, comparto) sino que oculte el carácter moral del razonamiento que lo lleva a adoptar esa decisión.

(11) Un derecho que se tomara en serio como absoluto anularía todos lo demás derechos y transformaría en inviable a la comunidad que adoptara un principio tan irracional de acción: las instituciones, que operarían solo para la satisfacción de ese derecho, tendrían como resultado hacer más que penosa la vida de sus miembros (ver Marquisio, 2018a). 
La Corte afirma que la citada disposición constitucional hace ingresar el derecho a la salud al ordenamiento jurídico y que su ingreso, sin argumentación adicional, decide la solución correcta del caso. Esto hace innecesario explicitar una teoría sobre cómo hay que leer la Constitución, el lugar que ocupa la mención de ese derecho en el contexto del conjunto de principios, valores y derechos a que hace referencia la Carta, la significación moral de esas alusiones o, inclusive, el modo apropiado de interpretar un texto que, en su literalidad, ni siquiera hace referencia a un "derecho a la salud". Desde esta visión, la incorporación de un estándar moral, por su mera mención, es capaz de determinar el derecho de modo pleno, dejando un margen nulo de discrecionalidad para intérpretes y aplicadores.

La incorporación como doctrina contrasta en su objetivo con la incorporación como teoría. Mientras la última tiene una ambición descriptiva, pues se limita a establecer lo que puede ser considerado como derecho para los sistemas jurídicos en general, la primera es prescriptiva: se plantea como un argumento sobre cómo deberían actuar los jueces a la hora de resolver casos concretos, que permite evitar exigencias argumentativas que consideramos inherentes al rol del juez, si asumimos una concepción no formalista de la decisión judicial.

La tesis de los positivistas inclusivos es, como se dijo antes, que la incorporación implica la incompletitud del derecho, que es una consecuencia de la necesidad de acudir al razonamiento moral para identificarlo, en cuanto este, aunque se postule una moral objetiva, es complejo, falible y sujeto a desacuerdo de buena fe. Por el contrario, la incorporación como doctrina prescribe al juez que no acuda al razonamiento moral pues la mera mención del principio le proporciona el criterio correcto para resolver el caso, haciendo irrelevantes consideraciones normativas ulteriores.

El incorporacionismo como doctrina, al igual que el positivismo inclusivo, se compromete con la existencia de un criterio de demarcación entre los estándares jurídicos y morales. Este criterio es convencional: el hecho de la aceptación de una constitución (como criterio de validez supremo), junto con supuestos meta constitucionales no explicitados(12), es la que determina que ciertos estándares morales pasen a formar parte del derecho. Sin embargo, la doctrina incorporacionista pretende que este concepto de derecho, criterial y convencional, tenga una significación normativa excluyente de los demás estándares, con el efecto de que su invocación sature las exigencias de justificación de la decisión judicial.

La doctrina incorporacionista no tiene respaldo en las concepciones teóricas contemporáneas más relevantes o influyentes (positivismo, iusnaturalismo,

(12) Para la distinción entre constitución y meta constitución, ver Alexander, 2009. 
antipositivismo). Sin embargo, en tanto es invocada como justificación de decisiones por un número importante de jueces (en especial, los que tienen la última palabra) genera el desafío de explicarla teóricamente. Mi planteo es que eso resulta posible a través de las categorías de la teoría del error.

\section{La teoría del error}

En términos generales, una teoría del error es un conjunto de argumentos que muestran que cierta área de discurso involucra creencias sistemáticamente falsas $\mathrm{y}$, en consecuencia, todos los juicios de esa área son falsos o, al menos, no verdaderos (Olson, 2018).

Aunque se han presentado teorías del error en diferentes ámbitos de la filosofía, su influencia se destaca en la metaética, a partir de la tesis de J. Mackie en cuanto a que los juicios morales tienen una necesaria pretensión de objetividad, pero, dado que no existen las propiedades morales que podrían hacerlos verdaderos, son irremediablemente falsos (Mackie, 1977) (13).

La teoría del error en metaética acepta que la moral pretende fuerza obligatoria, proporcionando razones categóricas para la acción, y que las creencias morales juegan un rol causal en muchas de nuestras acciones. Sin embargo, rechaza que los pretendidos deberes sean inescapables y que las creencias morales estén respaldadas por valores objetivos (Garner, 1994, p. 58).

Una explicación desde la teoría del error hace referencia a un ámbito de discurso y no a cada afirmación o uso de un término dentro de ese ámbito de discurso. El error se sostiene con relación a un cierto subconjunto de enunciados: aquellos que pueden entenderse como afirmando la instanciación de una propiedad específica, que en realidad no tiene contrapartida ontológica (Joyce y Kirchin, 2006).

La estructura general del argumento de Mackie es aplicable a un vasto dominio discursivo. Por ejemplo, si hablamos de brujas, hacemos referencia a mujeres con poderes sobrenaturales, aunque no creamos que existan realmente. Por tanto, si alguien hace una afirmación del tipo $F$ es una bruja, puede sostenerse que está realizando un juicio con aptitud de verdad, pero (desde nuestras creencias sobre las entidades que existen realmente en el mundo) inevitablemente falso (Kalf, 2018, p. 3).

(13) El propósito de Mackie era defender, partiendo de premisas cognitivistas, el escepticismo moral. Desde luego, su visión de lo que constituyen las "propiedades morales" (en que se basa el argumento de la "queerness" o "rareza") es controversial en metaética, y las teorías que sostienen la objetividad moral (realistas naturalistas y no naturalistas, quasi-realistas y constructivistas) tienen distintas visiones acerca de qué hay que entender por tales propiedades. 
Un ejemplo habitual de teoría del error es la evaluación de los enunciados de la religión desde la perspectiva del ateo. Numerosos juicios formulados por las distintas doctrinas religiosas (por ejemplo, debemos rezar diariamente) presuponen la creencia de que Dios existe y tienen aptitud de verdad pues serían verdaderos si Dios (con los atributos con que lo caracteriza la religión de que se trate), efectivamente existe. El ateo puede aceptar el valor veritativo de esos juicios, pero añadiendo que, en tanto no existe en el mundo ninguna entidad que los haga verdaderos, son irremediablemente falsos (ver Joyce, 2016, pp. 3-4).

Siguiendo a Joyce, se puede resumir una teoría del error en dos pasos. El primero es conceptual: establecer el significado del término o área de discurso (AD). El segundo es ontológico o sustantivo: mostrar que no existe alguna propiedad $x$ tal que, para el término o área de discurso en cuestión (AD), permitiría afirmar la verdad de (AD) $x$ (ver Joyce, 2001, pp. 4-5).

A su vez, el segundo paso requiere formular un argumento con estructura bipartita. La primera parte tiene que dar cuenta de por qué no existe la propiedad que presupone el ámbito de discurso en cuestión; demostrar su rareza, en comparación con un conjunto de creencias de aceptación generalizada. La segunda parte consiste en explicar por qué tendemos a hablar como si existiera determinada propiedad, aunque ello sea falso (Olsen, 2018).

Pero, dar por completa una teoría del error, requiere afrontar una tarea adicional, el denominado problema del ¿̇ahora qué? Se trata de contestar a la pregunta sobre qué deberíamos hacer una vez constatado el error generalizado acerca del término o área discursiva en cuestión. ¿Deberíamos renunciar a utilizar el término o realizar el conjunto de afirmaciones que sabemos equivocadas? ¿ $\mathrm{O}$ nuestra conclusión (de segundo orden) deja intocada la legitimidad de la práctica discursiva en cuestión?(14).

\section{El error de la doctrina de la incorporación}

Una explicación de la doctrina de la incorporación a través de la teoría del error requiere establecer qué propiedad o atributo de la realidad se presupone para que las proposiciones incorporacionistas sean verdaderas. Luego, mostrar que es falsa

(14) En filosofía moral, el problema del ahora qué da lugar a distintas metaéticas prescriptivas de la teoría del error: el ficcionalismo revolucionario, según el cual deberíamos simular que la moral existe; el expresivismo revolucionario, que plantea que deberíamos usar el lenguaje moral para expresar estados no conativos (y no como realmente lo usamos, para realizar afirmaciones con pretensión veritativa); el conservacionismo, la tesis de que deberíamos conservar el discurso moral tal como es, aunque sepamos de su error fundamental; y el abolicionismo, según el cual deberíamos dejar de utilizar por completo el discurso moral (Kalf, 2018, pp. 159-162). 
esa presuposición y por qué, sin embargo, se tiende en la práctica a argumentar como si fuese verdadera. Y, finalmente, sugerir cómo debería afectar la identificación del error a la práctica sustentada en dicha doctrina.

El ámbito que aquí tomamos como realidades el sistema jurídico tal como lo caracteriza la teoría de la incorporación. Debemos suponer que dicha teoría es correcta y que las fuentes sociales permiten de modo contingente que criterios de contenido moral constituyan condiciones de validez jurídica: la moral pasa a integrar el derecho por autorización de las fuentes sociales. La incorporación como doctrina requiere que, del ingreso de los principios al derecho, se deriven criterios de resolución de los casos generales y particulares; criterios concluyentes, en el sentido de excluir los argumentos normativos potencialmente aplicables (reglas legales o constitucionales, universo de razones morales relevantes).

En el caso citado como ejemplo, el fallo de la Corte presupone: a) que los derechos y principios morales se incorporan a través de actos de las fuentes sociales (la teoría de la incorporación); b) que el derecho absoluto a la salud se incorpora al derecho por el hecho de la aprobación del texto constitucional; c) que la incorporación del derecho a la salud absoluto permite resolver, sin más, cualquier controversia jurídica que se interprete como un caso de limitación a ese derecho.

Si tomamos como verdaderos los enunciados a) y b) es clara la falsedad de c). La teoría de la incorporación requiere que c) sea falso. Si el derecho a la salud significa el ingreso de la moral política al sistema jurídico la consecuencia es una incompletitud fundamental de este.

En una comunidad que ha incorporado, por referencia constitucional, el derecho a la salud, las prestaciones médicas que las instituciones médicas deben a sus miembros están jurídicamente indeterminadas, porque existen múltiples criterios potenciales para su determinación. El papel del juez en la decisión de una controversia sobre el punto será, precisamente, determinarlas para el caso concreto (o con los efectos propios de la sentencia) y ello puede implicar desaplicar disposiciones legislativas que regulan la cuestión.

El ingreso del derecho a la salud obliga, en los casos donde está en juego una alegada afectación a este, a los jueces a formular una teoría acerca de los requerimientos abstractos de moral política que ese derecho (teniendo en cuenta otros derechos que también han ingresado por la propia constitución) conlleva, para luego evaluar cualquier ley en concreto que regule o limite las prestaciones de salud de la comunidad.

Supongamos que la ley excluye de las prestaciones de saludes generales o gratuitas requerimientos tan básicos como las vacunas. Es probable que la teoría moral que necesiten los jueces para resolver un caso donde estas prestaciones sean 
reclamadas sea bastante sencilla. Una vez que ha ingresado el derecho a la salud, puede suponerse que existe una obligación de los gobiernos de garantizar el acceso universal a esta clase de tratamientos básicos y que ello es armonizable sin mayores dificultades (al menos en condiciones políticas y sociales normales) con los requerimientos de otros derechos.

Pero ese no es el caso, por ejemplo, de los tratamientos experimentales o los medicamentos de muy alto costo, donde la garantía de acceso universal (el nivel hasta donde llega la cobertura incondicional) requiere su articulación con un vasto número de necesidades sociales, que también reclaman satisfacción institucional. En estos casos, el razonamiento que se exige a los jueces para determinar el derecho es mucho más sofisticado (Marquisio, 2018a). Pero el punto es que en ambos casos se trata de argumentaciones normativas que, aunque con distinto grado de complejidad, deben ser formuladas por los jueces como consecuencia del ingreso al derecho de los estándares morales.

En conclusión: es falsa, desde los supuestos básicos de la teoría de la incorporación (T), la doctrina de que la incorporación de la moral al sistema jurídico determina el derecho aplicable y constituye una razón concluyente para las decisiones judiciales (D). Sin embargo, (D) es un tópico aceptado en la fundamentación de sentencias y en la construcción de doctrinas interpretativas. ¿Por qué ocurre esto?

Para ensayar una explicación, vuelvo al debate Hart-Dworkin.

Tal como observaba Dworkin, en su crítica inicial al modelo de las reglas, los principios son invocados por los participantes de la práctica jurídica, bajo el supuesto de que se trata de estándares obligatorios y se ubican dentro de los límites del derecho. Para Dworkin, esto demostraba que la regla de reconocimiento era falsa, por su imposibilidad de dar cuenta de todos los estándares que forman parte del derecho vigente, en una comunidad y en un momento determinado.

Sin embargo, desde el punto de vista del primer Dworkin, los principios hacían más determinado el derecho solo en un sentido ideal, es decir como el (hipotético) resultado del razonamiento de un juez con conocimiento absoluto y tiempo ilimitado. Para los jueces reales, la invocación de los principios viene acompañada de la carga de argumentar por qué un principio o una cierta constelación de principios imponen la mejor solución a cualquier caso concreto. De hecho, su ejemplo estrella, el célebre Riggs vs. Palmer, es un caso donde los jueces contraponen argumentaciones morales acerca de si una regla jurídica debe ser conservada o cambiada (Dworkin, 1967).

Según Hart, aunque puede aceptarse que los jueces expresan en sus fallos sentirse obligados por los principios morales, su discurso no debe ser tomado en 
sentido literal pues, por razones institucionales, no les conviene hacer evidente su discrecionalidad, admitiendo que se apartan del derecho y acuden a la moral para resolver los casos difíciles. Sin embargo, Hart acepta que la regla de reconocimiento incorpora, de modo contingente, principios morales que pasan a formar parte del derecho (Hart, 1994).

Puede apreciarse, entonces, que la doctrina incorporacionista es el resultado de sumar dos equívocos. Por un lado, Dworkin invoca a los principios en contraposición lógica con las reglas, dando a entender que hay dos tipos de "entidades jurídicas": reglas (enunciados de origen, provenientes de las fuentes sociales) y principios (estándares de contenido, provenientes de la moral). Por otro lado, Hart, aunque rechaza otras críticas de Dworkin, acepta la idea de que los principios provienen de la moral, pero afirmando que es su incorporación — por la regla de reconocimiento - al derecho lo que les otorga su fuerza normativa.

Dworkin utilizó la contraposición reglas/principios para mostrar como la normatividad de los estándares morales no podía provenir de una convención. Hart rechazó esa contraposición y aceptó que los principios morales podían formar parte del derecho, pero les atribuyó una fuerza normativa convencional a través de la incorporación.

El resultado es un discurso que concibe al sistema jurídico como compuesto por dos entidades: las reglas (legislación) derrotables y los principios incorporados convencionalmente por la constitución o los pactos internacionales, con fuerza normativa absoluta o concluyente para derrotar a las reglas.

Esta suma de malentendido permite a los jueces ubicarse en el mejor de los mundos posibles, cuando desean que permanezca oculto el hecho de que crean y modifican reglas jurídicas acudiendo, entre otras cosas, al razonamiento moral. Por un lado, toman como correcta la contraposición reglas/principios del primer Dworkin(15). Por otro lado, asumen que la fuerza normativa de los principios no proviene de su justificación moral, sino que tiene un origen convencional. La doctrina de la incorporación proporciona así a los jueces el discurso óptimo para encubrir su discrecionalidad y evitar el reconocimiento de la apertura a consideraciones que puedan ser percibidas socialmente como extrajurídicas.

Los jueces tienen fuertes intensivos para utilizar la doctrina que mejor los presenta como meros aplicadores del derecho y, al mismo tiempo, les otorga el poder de desaplicar o modificar virtualmente el conjunto de la legislación vigente.

(15) Contraposición que Dworkin, su obra tardía, consideró un malentendido (ver Marquisio, $2018 b)$. 
En resumen, una explicación de la doctrina de la incorporación en términos de la teoría del error puede resumirse en los siguientes términos: I) esta doctrina significa que la incorporación determina, por si sola, el derecho aplicable a los casos jurídicos (propiedad D); II) dando por correcta la teoría de la incorporación (T),(D) es falsa porque resulta incompatible con uno de sus supuestos básicos, la incompletitud del sistema jurídico como consecuencia del ingreso de estándares morales; III) los jueces invocan (D) porque tienen evidentes incentivos institucionales para ello: se trata de una forma óptima de encubrir su discrecionalidad, presentando los problemas jurídicos como previamente resueltos por la constitución, sin necesidad de acudir al razonamiento moral y su incómoda controversia inherente.

\section{VII. ¿Y ahora qué?}

El rasgo distintivo del derecho moderno es su institucionalidad: la creación, identificación y aplicación de estándares jurídicos es obra de seres humanos a los que ciertas reglas han atribuido el rol de autoridades. En el carácter constitutivo de este rasgo están de acuerdo positivistas, iusnaturalistas y antipositivistas.

Qué el derecho sea una creación humana lleva de suyo la falibilidad de todo el proceso de su elaboración, identificación y aplicación. Los estándares jurídicos pueden ser deficientes, equivocados, injustos o hasta perversos. Y cualquier teoría sobre el derecho que no tome en cuenta este truismo está destinada a no ser tomada en serio.

El problema con la doctrina de la incorporación es que aporta a la decisión judicial - y a través de ella a todo el derecho- un defecto adicional: la hipocresía. Se acepta que los casos jurídicos se resuelvan bajo motivaciones contradictorias con los propios supuestos teóricos que invocan.

La doctrina de la incorporación es un síntoma del problemático vínculo que existe entre los ciudadanos de las democracias contemporáneas y las instituciones que contribuyen a crear o sostener. A través de la sanción de constituciones largas, los ciudadanos atribuyen a los jueces un enorme poder de creación de derecho. Luego, ese poder es encubierto por la doctrina de la incorporación, que presenta a todos los casos como resueltos en forma previa a la decisión, a partir del hecho la sola mención constitucional de algún principio. De este modo, el sistema jurídico funciona como un modo muy eficiente de eliminación de la responsabilidad individual y colectiva. En última instancia, pareciera que nadie crea derecho.

Dejar de lado el discurso incorporacionista tendría como efecto una práctica jurídica más sincera, pero también implicaría que ciudadanos, gobernantes y jueces asumieran la responsabilidad que les toca en cuanto a la realización del 
mundo social común (Christiano, 2006). Si los ciudadanos van a delegar en los jueces la resolución de trascendentes asuntos sociales, como el conjunto de prestaciones médicas que cada persona tiene derecho a recibir, ello debería, al menos, quedar claro para todos los involucrados, desde distintos roles, en ese proceso. El razonamiento moral, que debería ser la base del voto de cada ciudadano en un contexto de deliberación pública que acompañe la elección de los gobernantes, puede ser delegado en los jueces, sin necesidad de que se encubra su condición de tal.

La importancia de evitar el estado de insinceridad colectiva en que nos ubica la doctrina de la incorporación es un argumento para, como sugiere Dworkin, dejar de pensar al derecho y la moral como dos sistemas separados, donde el primero - como Rey Midas - extrae estándares de la segunda y les proporciona fuerza normativa. Si la moral es el conjunto de razones que tenemos para actuar considerando los intereses de otros, las instituciones que llamamos jurídicas solo pueden ser entendidas como mecanismos - muy complejos y siempre discutibles- a través de los cuales una sociedad cumple con las responsabilidades morales que en cada momento histórico logra identificar.

Así, la supuesta incorporación puede ser entendida, a lo sumo, como una metáfora de la relevancia institucional que se atribuye a un estándar moral y del hecho de que este debe ser tenido en cuenta de forma necesaria para resolver determinados conflictos sociales. Desde luego, esto supone que el derecho no puede ser aplicado sin acudir a consideraciones de filosofía política y moral, lo que sugiere un cambio de base en la formación de los juristas y, en especial, de los jueces.

\section{Conclusiones}

La teoría de la incorporación (T) es uno de los temas principales de discusión en la filosofía jurídica contemporánea. Sea o no correcta (T), la doctrina de la incorporación (D) que la presupone, resulta falsa. Si (T) es falsa, entonces, cualquier pretensión doctrinal de resolver un caso por el argumento de la incorporación, carece de sustento, pues la moral no puede formar parte del derecho. Si (T), en cambio, es correcta, una de sus implicaciones es la incompletitud del derecho; por tanto, (D) en cuanto pretende que la incorporación lo hace completo (los estándares incorporados determinan la solución correcta de casos generales y particulares), resulta falsa.

La doctrina de la incorporación es un error generalizado, para cuya comisión los jueces tienen importantes incentivos institucionales. Una mejor valoración de los fundamentos de la democracia, entendiéndola como un compromiso que surge de la responsabilidad última de cada ciudadano por el mundo social común, 
debería resultar en la adopción de una práctica jurídica sincera, lo que constituye un argumento para el abandono de esta doctrina.

\section{Bibliografía}

Alexy, R. (1997). Teoría de la Argumentación Jurídica. La teoría del discurso racional como teoría de la fundamentación jurídica. Madrid: CEC.

Atienza, M. (1997). Los límites de la interpretación constitucional. De nuevo sobre los casos trágicos. Isonomía, vol. (6) (pp. 7-30).

Alexander, L. (2009). Constitutionalism. En T. Christiano, y J. Christman, Contemporary Debates in Political Philosophy (pp. 283-299). Malden: Wiley-Blackwell.

Atria, F. (2016). La forma del derecho. Madrid: Marcial Pons.

Bovino, A y Courtis, C. (2009). Por una dogmática conscientemente política. En C. Courtis (comp.), Desde otra mirada. Textos de Teoría Crítica del Derecho (pp. 303-342). Buenos Aires: Eudeba.

Bulygin, E. (2004). ¿Está parte de la filosofía del Derecho basada en un error? Doxa, vol. (27) (pp. 15-26).

Coleman, J. (2009). Beyond Inclusive Legal Positivism. Ratio Juris, vol. (22) 3 (pp. 359-394).

Christiano, T. (2010). The Constitution of Equality: Democratic Authority and its Limits. New York: Oxford University Press.

Dickson, J. (2012). Legal Positivism: Contemporary Debates. En A. Marmor (ed.), The Routledge Companion to Philosophy of Law (pp. 48-64). New York: Routledge.

Dworkin, R. (1967). The Model of Rules. The University of Chicago Law Review, vol. (35) (pp. 14-46).

Dworkin, R (2006). Justice in Robes. Cambridge (MA): Belknap Press.

Dworkin, R (2011). Justice for Hedgehogs. Cambridge (MA): Belknap Press.

Finnis, J. (2011). Natural Law and Natural Rights. Second Edition. New York: Oxford University Press.

Finnis, J. (1999). The Truth in Legal Positivism. En R. P. George, The Autonomy of Law. Essays on Legal Positivism (pp. 195-214). New York: Oxford University Press. 
Finnis, J. (2016). Natural Law Theories. En E. N. Zalta (ed.), The Stanford Encyclopedia of Philosophy. Recuperado de https://plato.stanford.edu/archives/ win2016/entries/natural-law-theories/ [Fecha de consulta: 27/03/2019].

Garner, J. (1994). Beyond Morality. Brattleboro: EPBM.

Hart, H. L. A. (1994). The Concept of Law. Second Edition. New York: Oxford University Press.

Kalf, W. F. (2018). Moral Error Theory. Cham: Palgrave McMillan.

Joyce, R. (2001). The Myth of Morality. New York: Cambridge University Press.

Joyce, R. (2016). Essays in Moral Skepticism. New York: Oxford University Press.

Joyce, R. y Kirchin, S. (2006). Introduction. En R. Joyce y S. Kirchin (eds.), $A$ World Without Values. Essays on John Mackie's Moral Error Theory. Dordrecht: Springer.

Leiter, B. (2010). Legal Formalism and Legal Realism. What is the Issu. Legal Theory, vol. (16) (2) (pp. 111-133).

Mackie, J. L. (1977). Inventing Right and Wrong. London: Penguin Books.

Marquisio, R. (2017a). Tres modelos de pospositivismo jurídico. Revista Anales de la Facultad de Ciencias Jurídicas y Sociales, Universidad de La Plata, vol. (No 47) (pp. 864-885). Buenos Aires: La Ley.

Marquisio, R. (2017b). El ideal de autonomía moral. Revista de la Facultad de Derecho, UDELAR, vol. (No 43) (pp. 55-92).

Marquisio, R. (2018a). Los derechos inherentes: una interpretación moral. A propósito de la lectura formalista del artículo 173 de la Constitución de 1917. Anuario del Área Socio-Jurídica. Faculta de Derecho. UDELAR, vol. (10) (pp. 16-31).

Marquisio, R. (2018b). El constitucionalismo de Ronald Dworkin y su teoría del derecho como moral política institucionalizada. Revista Anales de la Facultad de Ciencias Jurídicas y Sociales, Universidad de La Plata, vol. (No 48) (pp. 1107-1128). Buenos Aires: La Ley.

Marmor, A. (2016). Convenciones, razones y derecho. En L. Ramírez Ludueña y J. Vilajosana (eds.), Convencionalismo y Derecho (pp. 67-88). Madrid: Marcial Pons.

Moore, M. (1992). Law as a Functional Kind. En R. P. George (ed.) Natural Law Theory. Contemporary Essays (pp. 188-242). New York, Oxford University Press. 
Moreso, J. J. (2015). Positivismo contemporáneo. Enciclopedia de Filosofía y Teoría del Derecho, vol. (1) (pp. 171-205). México (DF): UNAM.

Núñez Vaquero, A. (2015). Ciencia jurídica. En J. Fabra Zamora y A. Núñez Vaquero (coord.), Enciclopedia de filosofía y teoría del derecho, vol. (I) (pp. 601-631). México D.F.: UNAM.

Olson, J. (2018). Error Theory in Metaethics. En T. McPherson y D. Plunkett (eds.), The Routledge Handbook of Metaethics (pp. 58-71). New York: Routledge.

Pino, G. (2014). Positivism, Legal Validity and the Separation of Law and Morals. Ratio Juris, vol. (27), № 2 (pp. 190-217).

Raz, J. (1999). Practical Reason and Norms. New York: Oxford University Press.

Raz, J. (2009). The Authority of Law. Essays on Law and Morality. New York: Oxford University Press.

Raz, J. (2013). Entre la autoridad y la interpretación (pp. 194-199). Madrid: Marcial Pons.

Ruiz Miguel, A. (2002). La dogmática jurídica: ¿ciencia o técnica? En A. Cabanilla Sánchez (coord.), Estudios jurídicos en homenaje al profesor Luis Díez-Picazo, vol. (4) (pp. 5649-5680). Madrid: Civitas.

Shapiro, S. (1998). On Hart's Way Out. Legal Theory, 4/4 (pp. 469-508).

Shapiro, S. (2009). Was Inclusive Legal Positivism Found on a Mistake. Ratio Juris, vol. (22), № 3 (pp. 326-338).

Sinnott-Amstrong, W. (2006). Moral Skepticisms. New York: Oxford University Press.

Tovagliare, F.; Van Rompaey, L. y Barbieri, L. (2016). Aplicación directa de principios y normas constitucionales. Montevideo: La Ley.

Fecha de recepción: 28-03-2019 Fecha de aceptación: 23-09-2019 